\title{
Boredom makes me 'nervous': fidgeting as a strategy for contrasting the lack of variety
}

\section{Orlando Ricciardi, Piero Maggi and Francesco Di Nocera*}

\author{
Department of Psychology, \\ Sapienza University of Rome, \\ Via dei Marsi, 78, \\ 00185 Rome, Italy \\ Email: orlando.ricciardi@uniroma1.it \\ Email: piero.maggi@uniroma1.it \\ Email: francesco.dinocera@uniroma1.it \\ *Corresponding author
}

\begin{abstract}
Vigilance decrement is a relevant problem in critical contexts requiring occasional response after a prolonged period of inactivity. Although many studies describe boredom as the leading cause in depleting attentional resources, the understanding of its relationship with human performance has been limited by the unavailability of objective measures. This study attempts to overcome this limitation by focusing on fidgeting (namely, repetitive and involuntary body movements) as a behavioural correlate of boredom. A laboratory study was devised for comparing the individuals' performance to two versions of the same task characterised by two boredom levels. Movements were detected using accelerometers controlled by an Arduino board. Results showed that participants fidgeted more in the condition operationalised as less boring than in the more boring one. Result of this study are interpreted as supporting the idea that an increase in fidgeting may have a functional role, and that it might be used by individuals for introducing variability where it lacks. Overall, fidgeting appears to be promising candidate measure for that could be used in many operational settings for the assessment of the operator functional state.
\end{abstract}

Keywords: boredom; monotony; mental workload; fidgeting; human performance; typing.

Reference to this paper should be made as follows: Ricciardi, O., Maggi, P. and Di Nocera, F. (2019) 'Boredom makes me 'nervous': fidgeting as a strategy for contrasting the lack of variety', Int. J. Human Factors and Ergonomics, Vol. 6, No. 3, pp.195-207.

Biographical notes: Orlando Ricciardi received his Masters in Work and Organizational Psychology from the Sapienza University of Rome, Italy, where he is now enrolled in the PhD program in Psychology and Cognitive Science. He is a member of the Eye-Tracking Laboratory, a facility of the Department of Psychology, where he is involved in several research lines including those on reading, vigilance, and mental workload.

Piero Maggi received his Masters in Psychology of Communication and Marketing from the Sapienza University of Rome, Italy, where he is now enrolled in the PhD program in Psychology and Cognitive Science. He is a 
member of the Eye-Tracking Laboratory, a facility of the Department of Psychology, where he is involved in several research lines including those automation, vigilance, and mental workload.

Francesco Di Nocera received his $\mathrm{PhD}$ in Psychology from the Sapienza University of Rome, Italy, where he now serves as an Associate Professor of Work and Organizational Psychology at the Department of Psychology. So far, he contributed to the field of human factors with research studies on a great variety of topics including mental workload, human error, and adaptive automation. At the Department of Psychology, he coordinates the activity of the Eye-Tracking Laboratory.

This paper is a revised and expanded version of a paper entitled 'Fidgeting as a sensory reinforcement strategy for overcoming boredom' presented at Human Factors and Ergonomics Society, Europe Chapter annual meeting, Berlin, $8-10$ October 2018.

\section{Introduction}

Vigilance decrement is a relevant problem in critical contexts requiring occasional response after a prolonged period of inactivity such as cockpits, air traffic control, military surveillance, quality process control in industrial settings, long-distance driving and agricultural inspections (Dorrian et al., 2007; Hartley et al., 1989; McBride et al., 2007; Proctor and Van Zandt, 1994; Satchell, 1993).

The phenomenon has been widely explained as depletion of attentional resources. Still, there is no agreement on how these resources are consumed. Two widely accepted theoretical accounts refer to cognitive overload (Caggiano and Parasuraman, 2004; Head and Helton, 2015; Helton et al., 2005; Helton and Russel, 2011, 2012, 2015; Helton and Warm, 2008; Parasuraman, 1979; Stearman and Durso, 2016; Tiwari et al., 2009) and cognitive underload (Esterman et al., 2016, 2015, 2014; Hopstaken et al., 2016, 2015; Morgan et al., 2014; Rosenberg et al., 2013) to explain the performance decrement in vigilance tasks. Although both theories address the boring nature of the task, they differently interpret the consequences of boredom (or monotony). Indeed, the attentional resources are supposed to be taxed by the effort to remain engaged with the task (Caggiano and Parasuraman, 2004) or, in the underload approach, by activities unrelated to the task (Scerbo et al., 1992; Manly et al., 1999; Robertson et al., 1997; Scerbo, 1998). In this second approach, activities unrelated to the task are used as a strategy to cope with boredom.

The importance of boredom and its effects on performance is becoming crucial in relation to the pervasiveness of automated system (Joyce, 2018; van Hooff and van Hooft, 2014) with several studies focusing on the role of boredom at the workplace. Thompson et al. (2006), for example, studied the performance of operators engaged in aircraft remote control showing that prolonged vigilance tasks are associated to feelings of boredom, monotony and invariability that, in turn, is associated with a decrement in arousal. Cummings et al. (2016) emphasised the need for the individual to look for other activities to stay alert during boring tasks.

An official definition of boredom is provided by the International Organization for Standardisation (ISO), that defines boredom as a 


\begin{abstract}
"Slowly developing state of reduced activation which may occur during long, uniform, repetitive tasks or activities and which is mainly associated with drowsiness, tiredness, decreasing and fluctuating performance, reductions in adaptability and responsiveness, as well as an increase in variability of heart rate often associated with/facilitated by long, uniform, repetitive task performance." (ISO 10075-1, 2019)
\end{abstract}

As reported by Smith (1981), who provided a review of studies on boredom of interest in the field of the human factors/ergonomics (HF/E) community, early academic studies on boredom were conducted by Barmack $(1937,1939 a, 1939 b)$ in the 1930s. He associated boredom with the lack of motivation that people feel while performing an activity. His interpretation of this feeling implies a conflict between the need to perform a task and the tendency to avoid it, in search of something more stimulating. Barmack was also the first who devised experimental studies on boredom with a structured methodology. The procedure he described consists of a combined approach including physiological, subjective and performance recordings. As a matter of fact, this approach has become a standard in the field of HF/E, as other phenomena (e.g., mental workload) are approached with the same multi-level rationale. Although boredom was not a simple problem to solve both in theory and application, many studies have been carried out during the "40s and '50s. In Hulin and Blood (1968) provided a definition of boredom as the perception of the sameness of the job from minute to minute, with a focus on unchanging characteristics. A recent and comprehensive definition of boredom can be found in Bench and Lench (2013), who describe the behavioural, cognitive, experiential and physiological levels of the boredom state. Other authors have described its emotional appearance (Pekrun et al., 2010), arousal activation (Schaufeli and Salanova, 2014), relation with the attentional state (Martin et al., 2012), psychophysiological state (O'Hanlon, 1981), its relation with the loss of satisfaction (Barbalet, 1999), as well as the negative association with the feeling of satisfaction (Fahlman et al., 2013; Perkins and Hill, 1985) and the sense of engagement in the current activity (Fahlman et al., 2009).

Despite a long tradition on boredom, the impact of task characteristics remained undefined until the study by Johansson (1989). She compared two different activities both leading to boredom, but in different ways. This is exemplified by the description of two types of jobs: assembly line and control room operators. The former must face with an uneventful task, whereas the latter does a high repetitive work. A limit of her study is that monotony can be considered either a cause or a consequence of the activity.

According to the definitions provided above, boredom can be studied at the subjective, psychophysiological and behavioural level. This research area often relies on subjective surveys, as the boredom proneness scale by Farmer and Sundberg (1986), the boredom susceptibility scale by Zuckerman et al. (1964) or the multidimensional state boredom scale by Fahlman et al. (2013). However, subjective reports are vulnerable to biases, expectations, and context effects. Also, they cannot provide real-time information on boredom, which may change over time.

\title{
2 On the need for variability
}

The lack of meaning is one of the characteristics of the task most frequently associated with boredom (Daniels et al., 2015; Gemmill and Oakley, 1992; Martin et al., 2006; Pattyn et al., 2008; van Tilburg and Igou, 2012). Generally speaking, the feeling of 
performing a meaningless activity is probably one of the most common experiential components associated with boredom and it is perceived as not intrinsically rewarding.

While carrying out boring tasks, people often report a willingness to escape, to do something else. The association between the perception to perform a uniform or repetitive activity and the desire to introduce variability has been long recognised and such variability can be observed both at the cognitive and physical level.

For example, the concept of mind wandering has been used to describe the tendency to decrease task engagement by focusing on own thoughts and internal states. Many authors have provided several definitions, such as 'task-unrelated images and thoughts' (Giambra, 1995; Carriere et al., 2013), or 'stimulus-independent thoughts', 'mind pops', and 'zone outs' (Carriere et al., 2013). Seli et al. (2016) described two different components of mind wandering: unintentional and intentional. Intentional mind wandering would be endogenous in nature involving a 'wilful' shift to some content, whereas the unintentional mind wandering would be exogenous reflecting the process of attentional capture. Earlier, Giambra (1995) described spontaneous mind wandering as a failure of executive control, emphasising the consequences of this behaviour. Other authors considered intentional mind wandering as a deliberate behaviour (Carriere et al., 2013; Schooler, 2002; Seli et al., 2016) that may be mostly innocuous, or even beneficial (Mooneyham and Schooler, 2013; Franklin et al., 2013), though frequently resulting in costly errors and accidents (e.g., Knowles and Tay, 2002) with deleterious consequences for the individual.

A different strategy to cope monotony is an increase in physical activity. Galton (1885) already reported this phenomenon in the course of a conference "when the audience is bored the several individuals cease to forget themselves, and they begin to pay much attention to the discomforts attendant on sitting long in the same position. They sway from side to side, each in his own way." A link between the act of sustaining attention and body movements was purported in the same years by Ribot (1890) in The Psychology of Attention. According to Ribot, "the activity of the mind and the activity of the body are importantly and inextricably linked."

More recently, Mehrabian and Friedman (1986) suggested that body movements may serve as a compensatory activity in absence of external stimulation. They named these movements 'fidgeting': the act of engaging in manipulations of one's body parts or other objects, such actions being peripheral or nonessential to central ongoing events or tasks (Mehrabian and Friedman, 1986). As Ribot (1890) separated attention devoted to internal events and to external object, Mehrabian and Friedman (1986) distinguished 'self-manipulation' from 'object-manipulation'. Woods and Miltenberger (1996) defined fidgeting as hair, face, and object manipulation; object mouthing; and repetitive movement of the limbs. In general, fidgeting is characterised by spontaneous and involuntary body movements; it's a superfluous motor activity, off-task behaviour, parallel to another task but not correlated or oriented to it (Carriere et al., 2013; Seli et al., 2014). Typically, fidgeting includes shifting on the chair, playing with jewellery or hair, repeated head motions, and other body movements. Mehrabian and Friedman (1986) have proposed to consider fidgeting as a 'state', a transient behavioural variable, or 'trait', a stable behavioural pattern and personality-related variable. They also make a list of all possible behaviours related to fidgeting, introducing many everyday actions. However, the idea of a 'fidgeting proneness', occasionally ascribed to temperamental differences, has not received much support in the literature (Putnam et al., 2006). Nevertheless, it is conceivable that the individual learning history might play a role in the 
production of aimless behaviours as well as in the selection of the circumstances in which they are produced.

Fidgeting is often associated and analysed along with several attention-related phenomena such as vigilance, boredom and mental workload. Restlessness episodes are indeed detected when the person is no longer engaged in the task that is performing. Seli et al. (2014) for example, have studied mind-wandering episodes associated with motor activity during a simple control task. Although they demonstrate a strong correlation between the two phenomena, they however consider them as contingently correlated effects of task disengagement.

Carriere et al. (2013) also found that a lack of attention was associated with an increase in fidgeting. In their perspective, fidgeting would be an overt behaviour expressing internal mental state, therefore usable as a behavioural indicator of the attention state of individuals. Indeed, Farley et al. (2013, p.2) reported that "fidgeting can be taken as providing a physical indicator of attentiveness in so far as its adoption reflects an attempt to combat waning attention." Furthermore, they suggest an interpretation of fidgeting like 'mental break' from a boring task, an interruption or diversion from the monotony. Its function seem to be compensatory, therefore supporting Ribot's (1890) early intuition: "the fundamental role of the movements in attention, is to maintain the appropriate state of consciousness and to reinforce it."

With that in mind, the aim of the present work is to provide new evidence about the function of fidgeting: namely, that it is as an adaptive strategy aimed at introducing variability and keep up with the boring task. Here this will be obtained by comparing fidgeting in two differently boring experimental conditions: an increase in fidgeting when boredom increases would provide support to our functional hypothesis and shed new light on this phenomenon.

\section{Method}

\subsection{Subjects}

Participants were 60 undergraduate students ( 28 females, mean age $=24.43, \mathrm{SD}=2.16$ ). All participants were native Italian speakers and were naïve as to the aims of the study, its expected outcomes, and the methodology of the experiment. They were randomly assigned to one of the two experimental conditions. This research complied with the tenets of the Declaration of Helsinki and was approved by the Institutional Review Board at the Department of Psychology, Sapienza University of Rome. Informed consent was obtained from each participant.

\subsection{Apparatus}

Participants wore two accelerometers for recording their motor activity. Accelerometers were applied only to the legs as the hands were used for performing the experimental task. The sensors were part of the Tinker Kit ADK Sensor Kit package associated with Arduino Mega 2560 Microcontroller Rev3. This instrument was calibrated through the development area (IDE) provided by the open-source Arduino Software. The device returned a default measure (values between 0 to 1,023) proportional to the acceleration according to a plane ( $\mathrm{x}, \mathrm{y}$ and $\mathrm{z}$-axis). Data were standardised using the following 
process: gravitational acceleration was subtracted by all recordings, due to its different effect on the $\mathrm{x}$ and $\mathrm{y}$-axis, to obtain exclusively the variations of acceleration between two successive epochs. To eliminate any micro-variation due to the approximation error of the instrument or to the intrinsic characteristics of human movement, movements smaller than one standard deviation were considered noise and therefore eliminated. The angular transformation was applied for stabilising variance and normalising proportional data [proportion of movements (Sokal and Rohlf, 1995)].

\subsection{Procedure}

First, participants wore the equipment composed of the sensors and the Arduino microcontroller. Sensors were described by the experimenter as generic 'psychophysiological' sensors on which they would be debriefed at the end. Participants were not aware of the fact that their movements were of interest in this study. Then they were required to space text presented as a very long string of uppercase letters $(28,356$ for 5,898 total words). The document, an article published in the online version of a major socio-political magazine, did not include any numbers and punctuation. In one condition, participants read the original text while spacing, so that the condition could be perceived as repetitive but meaningful. Besides, subjects in this condition received automatic feedback about their performance, as an error in spacing would appear immediately. In the other condition, the words composing the original text were randomised, making the condition both repetitive and meaningless. According to Helton and Warm (2008) and Langheim et al. (2007), an activity perceived as meaningless is most likely to be associated with boredom and sub-optimal performance. Consequently, in this experiment boredom was operationalised as lack of meaning. It should be also noted that the two versions of the task were otherwise identical, ruling out the effect of potential confoundings. Participants were instructed to use only the arrow keys and the spacebar. Given the very nature of the task, it was not possible for the participants to fidget with hands, but only with legs. No explicit time restrictions were communicated to the participants (who believed they had to space all the text), but the task was interrupted after 30 minutes. Participants were then debriefed and could ask questions regarding the experiment.

\section{Data analysis and results}

Angular transformation of the proportion of spaced words was used as the dependent variable in an ANOVA design using condition (meaningful vs. meaningless) as factor. Results showed an effect of condition (F1, $58=10.97, p<0.01, \eta 2 p=0.16)$ and the observed power was 0.91 , revealing a better performance for the meaningful (engaging) task group than the meaningless (boring) task group (Figure 1).

A second analysis was performed to analyse differences in legs movements. Angular transformations of legs movements were used as the dependent variable in an ANOVA design using condition (meaningful vs. meaningless) and leg (left vs. right) as factors. The effect of condition was statistically significant $(F 1,58=8.29, p<0.05, \eta 2 p=0.12)$ and the observed power was 0.81 confirming a greater proportion of movements for the meaningless task rather than the meaningful task (Figure 2). No differences between the left and right leg were found. 
Figure 1 Task performance expressed as the proportion of spaced words on total words composing the text (see online version for colours)

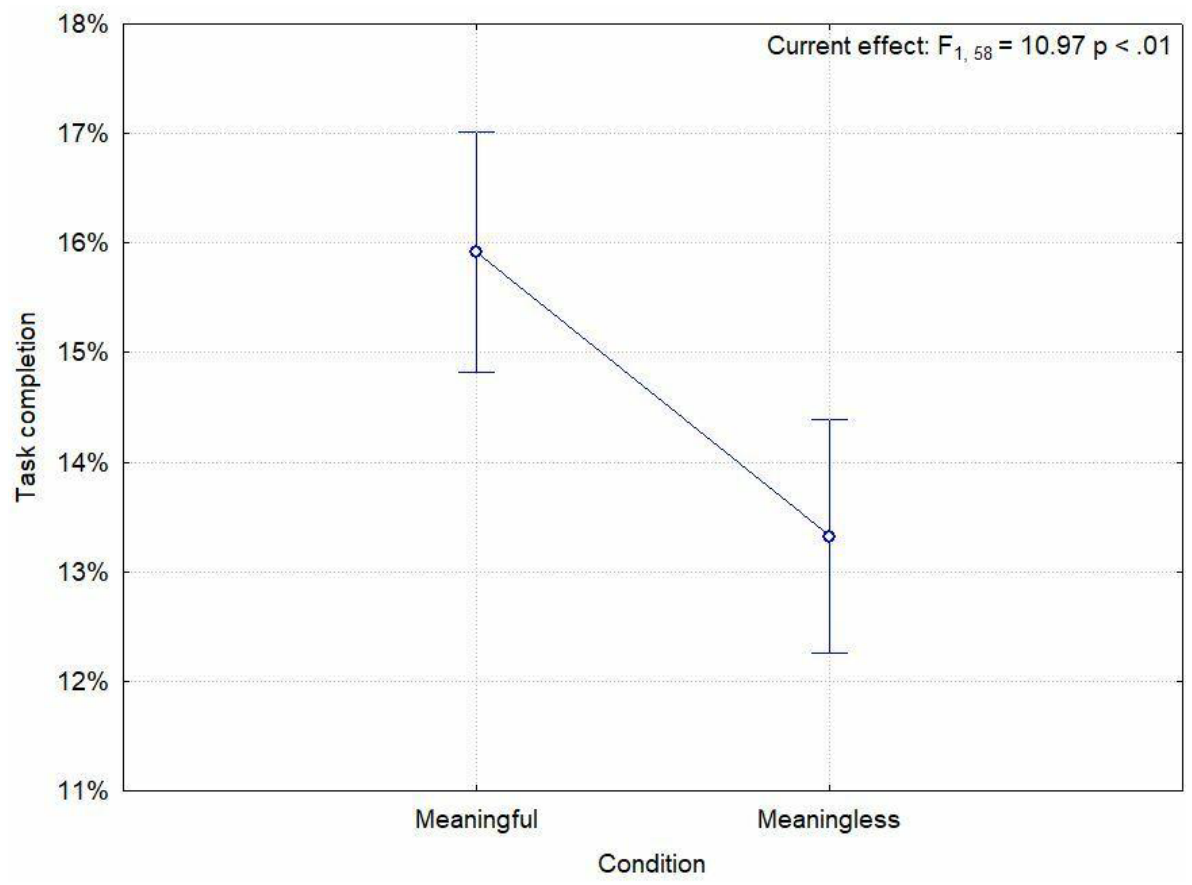

Figure 2 Fidgeting expressed as the proportion of legs movements (see online version for colours)

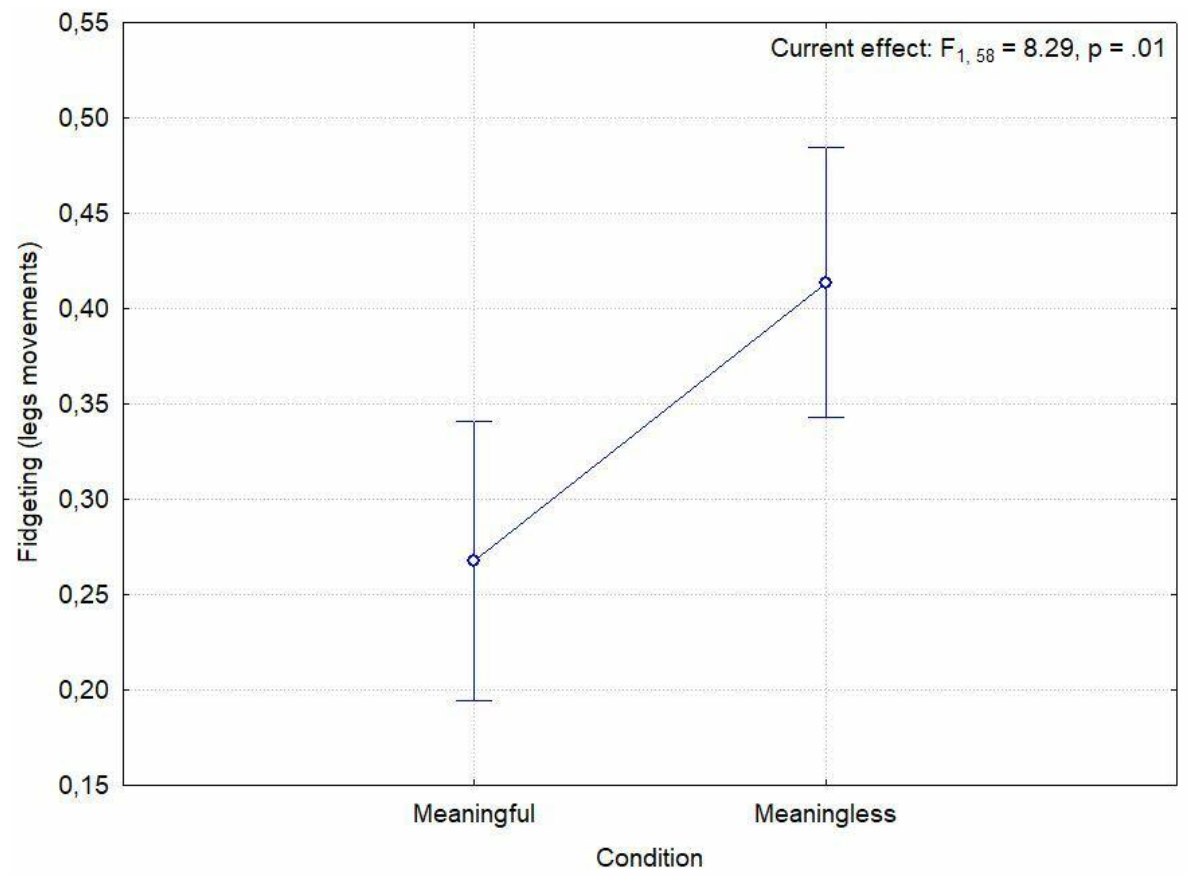




\section{Discussion}

The general objective of this work was to attempt the measurement of boredom using a behavioural outcome instead of subjective assessments. A valid metric for boredom would be very handy, because lack of attention due to monotony affects human performance not only in everyday settings, but also in highly complex environments (e.g., control rooms, ships bridges) where boring tasks may deplete attentional resources and/or lead to cognitive states that may jeopardise safety. When operators are faced with excessively high or excessively low task demands, they can become respectively overloaded or underloaded. Both those conditions may lead to an increase in error rates. Underload, which is of interest here, implies the need to cope with a boring activity and may result in a less than optimal performance. In these scenarios, safety is seriously compromised and in the literature, inattention, complacency, fatigue, monotony, mental saturation, mental satiation, reduced vigilance, and stress have been invoked as both causes and effects.

Body signals may be used for detecting boredom early. For example, a common physical reaction to unchanging stimulation is an increase in yawning. Provine and Hamernik (1986) reported that yawning can be considered a paralinguistic signal for drowsiness, fatigue, disinterest, and boredom. In work settings where the operator is continuously engaged, the individual may not only need to signal a discomfort but also to cope with the lack of variability denoting a situation as boring. Since Galton (1885) and Ribot (1890), fidgeting has been identified as the most common strategy for keeping attention to a boring task, and we hypothesised that this happens by introducing variability where it lacks. People often engages in spontaneous and involuntary body movements, superfluous motor activity, off-task behaviour such as shifting on the chair, playing with jewellery and hair, repeated head motions.

In the present study, we tested the hypothesis that fidgeting is a functional strategy to cope with boredom. More importantly, we provided evidence that a behavioural metric can be used for providing real-time information on the ongoing boredom state. In the present study we designed an experimental procedure in which participants were assigned to two groups performing two versions of the very same task except for one feature. In the first condition, reading a meaningful text automatically reinforced the correct activity. Indeed, performance in the meaningful condition was significantly better than performance in the meaningless condition. As expected, results also showed less fidgeting in the meaningful condition than in meaningless condition: the meaningless condition was associated with more legs movements (which can be properly considered fidgeting, because legs were not needed for performing the task). That is consistent with the idea that people may introduce variability through aimless body movements when engaging in a boring task. This result is consistent with Helton and Warm (2008) and Langheim et al. (2007), as the difference in body movements seems to confirm that people tend to increase aimless body movements when bored, and it is also consistent with the idea expressed by Schneider (2012) who suggested that variety can be considered as a reinforcer.

Although the present study employed a mundane task (text editing), which is also of interest of $\mathrm{HF} / \mathrm{E}$ research, it is methodological in nature. Our main scope was to test the relation between boredom (operationalised as lack of meaning) and aimless movements. Of course, the knowledge gathered from this first study needs to be tested in the field in order to verify whether it is actually useful in the different domains of interest for 
$\mathrm{HF} / \mathrm{E}$ research and applications (e.g., transportation, human-computer interaction, command-and-control). This would allow a better understanding of the phenomenon and the identification of specific strategies for detecting and measuring fidgeting. For example, the strategy used in this very study could be easily applied in contexts where the operator seats in front of a computer (e.g., operators in control rooms), but in the automotive context postural adjustments may be a more viable solution since it would be impossible or too cumbersome isolating aimless limbs movements. Such an approach has been already attempted by Di Nocera et al. (2014) in the maritime domain using movement sensors over a seat.

\section{Conclusions}

In conclusion, this study provided preliminary evidence that fidgeting may be usefully considered as an indicator of boredom. Results suggested that fidgeting has a functional role in coping with monotonous activity, and it is not only a sign of the boredom state as it has been often reported (see Mael and Jex, 2015; Eastwood et al., 2012). Furthermore, employing continuous behaviour for measuring boredom variations provides an opportunity for real-time measurement in operational settings. Of course, results from a single study cannot be considered exhaustive and other investigations are needed to better understand the relation between body movements, (lack of) variability and boredom.

Future studies should take into account the subjective experience of boredom to understand whether it is consistent with fidgeting and a real-world application would certainly need smaller, less invasive, wireless sensors.

In the present study only legs movement have been taken into account. Albeit this was unavoidable because of the very nature of the experimental task (involving the use of both hands), this may be considered a limitation of the study. Indeed, many manifestations of fidgeting often involve the use of hands (tapping, playing with hair, jewellery and other objects) and future studies should be devised for using tasks allowing subjects to fidget also with the upper limbs.

Notwithstanding all those limitations, one of the most important contribution of the present work is the operationalisation of boredom in terms of (lack of) meaningfulness of the task. Manipulation of the meaningfulness of the task was indeed successful and allowed to show differences in fidgeting although the motor activity underlying the two conditions was strictly the same.

\section{References}

Barbalet, J.M. (1999) 'Boredom and social meaning', The British Journal of Sociology, Vol. 50, No. 4, pp.631-646.

Barmack, J.E. (1937) 'Boredom and other factors in the psychology of mental effort: an exploratory study', Archives of Psychology, Vol. 218, No. 1, pp.6-81.

Barmack, J.E. (1939a) 'Studies on the psychophysiology of boredom: part I. The effect of 15 mgs. of benzedrine sulfate and 60 mgs. of ephedrine hydrochloride on blood pressure, report of boredom and other factors', Journal of Experimental Psychology, Vol. 25, No. 5, p.494.

Barmack, J.E. (1939b) 'Studies on the psychophysiology of boredom: part 2. The effect of a lowered room temperature and an added incentive on blood pressure, report of boredom, and other factors', Journal of Experimental Psychology, Vol. 25, No. 6, p.634. 
Bench, S.W. and Lench, H.C. (2013) 'On the function of boredom', Behavioral Sciences, Vol. 3, No. 3, pp.459-472.

Caggiano, D.M. and Parasuraman, R. (2004) 'The role of memory representation in the vigilance decrement', Psychonomic Bulletin \& Review, Vol. 11, No. 5, pp.932-937.

Carriere, J.S., Seli, P. and Smilek, D. (2013) 'Wandering in both mind and body: individual differences in mind wandering and inattention predict fidgeting', Canadian Journal of Experimental Psychology, Vol. 67, No. 1, pp.19-31.

Cummings, M.L., Gao, F. and Thornburg, K.M. (2016) 'Boredom in the workplace: a new look at an old problem', Human Factors, Vol. 58, No. 2, pp.279-300.

Daniels, L.M., Tze, V.M. and Goetz, T. (2015) 'Examining boredom: different causes for different coping profiles', Learning and Individual Differences, Vol. 37, No. 1, pp.255-261.

Di Nocera, F., Proietti Colonna, S., Dessì, F., Capobianco, C., Mastrangelo, S. and Steinhage, A. (2014) 'Keep calm and don't move a muscle: motor restlessness as an indicator of mental workload', in de Waard, D., Brookhuis, K., Wiczorek, R., Di Nocera, F., Barham, P., Weikert, C., Kluge, A., Gerbino, W. and Toffetti, A. (Eds.): Proceedings of the Human Factors and Ergonomics Society Europe Chapter 2013 Annual Conference, pp.183-191, ISSN 2333-4959 (online).

Dorrian, J., Roach, G.D., Fletcher, A. and Dawson, D. (2007) 'Simulated train driving: fatigue, self-awareness, and cognitive disengagement', Applied Ergonomics, Vol. 38, No. 2, pp.155-166.

Eastwood, J.D., Frischen, A., Fenske, M.J. and Smilek, D. (2012) 'The unengaged mind: defining boredom in terms of attention', Perspectives on Psychological Science, Vol. 7, No. 5, pp.482-495.

Esterman, M., Grosso, M., Liu, G., Mitko, A., Morris, R. and DeGutis, J. (2016) 'Anticipation of monetary reward can attenuate the vigilance decrement', PLoS One, Vol. 11, No. 7, p.e0159741.

Esterman, M., Liu, G., Okabe, H., Reagan, A., Thai, M. and DeGutis, J. (2015) 'Frontal eye field involvement in sustaining visual attention: evidence from transcranial magnetic stimulation', Neuroimage, Vol. 111, No. 8, pp.542-548.

Esterman, M., Reagan, A., Liu, G., Turner, C. and DeGutis, J. (2014) 'Reward reveals dissociable aspects of sustained attention', Journal of Experimental Psychology: General, Vol. 143, No. 6, pp.2287-2296.

Fahlman, S.A., Mercer, K.B., Gaskovski, P., Eastwood, A.E. and Eastwood, J.D. (2009) 'Does a lack of life meaning cause boredom? Results from psychometric, longitudinal, and experimental analyses', Journal of Social and Clinical Psychology, Vol. 28, No. 3, pp.307-340.

Fahlman, S.A., Mercer-Lynn, K.B., Flora, D.B. and Eastwood, J.D. (2013) 'Development and validation of the multidimensional state boredom scale', Assessment, Vol. 20, No. 1, pp.68-85.

Farley, J., Risko, E. and Kingstone, A. (2013) 'Everyday attention and lecture retention: the effects of time, fidgeting, and mind wandering', Frontiers in Psychology, Vol. 4, p.619.

Farmer, R. and Sundberg, N.D. (1986) 'Boredom proneness - the development and correlates of a new scale', Journal of Personality Assessment, Vol. 50, No. 1, pp.4-17.

Franklin, M.S., Mrazek, M.D., Anderson, C.L., Smallwood, J., Kingstone, A. and Schooler, J. (2013) 'The silver lining of a mind in the clouds: interesting musings are associated with positive mood while mind-wandering', Frontiers in Psychology, Vol. 4: 583.

Galton, F. (1885) 'The measure of fidget', Nature, Vol. 32, No. 187, pp.174-175.

Gemmill, G. and Oakley, J. (1992) 'The meaning of boredom in organizational life', Group \& Organization Management, Vol. 17, No. 4, pp.358-369.

Giambra, L.M. (1995) 'A laboratory method for investigating influences on switching attention to task-unrelated imagery and thought', Consciousness and Cognition, Vol. 4, No. 1, pp.1-21. 
Hartley, L.R., Arnold, P.K., Kobryn, H. and MacLeod, C. (1989) 'Vigilance, visual search and attention in an agricultural task', Applied Ergonomics, Vol. 20, No. 1, pp.9-16.

Head, J. and Helton, W.S. (2015) 'Passive perceptual learning versus active searching in a novel stimuli vigilance task', Experimental Brain Research, Vol. 233, No. 5, pp.1481-1489.

Helton, W.S. and Russell, P.N. (2011) 'Working memory load and the vigilance decrement', Experimental Brain Research, Vol. 212, No. 3, pp.429-437.

Helton, W.S. and Russell, P.N. (2012) 'Brief mental breaks and content-free cues may not keep you focused', Experimental Brain Research, Vol. 219, No. 1, pp.37-46.

Helton, W.S. and Russell, P.N. (2015) 'Rest is best: the role of rest and task interruptions on vigilance', Cognition, Vol. 134, No. 1, pp.165-173.

Helton, W.S. and Warm, J.S. (2008) 'Signal salience and the mindlessness theory of vigilance', Acta Psychologica, Vol. 129, No. 1, pp.18-25.

Helton, W.S., Hollander, T.D., Warm, J.S., Matthews, G., Dember, W.N., Wallaart, M. and Hancock, P.A. (2005) 'Signal regularity and the mindlessness model of vigilance', British Journal of Psychology, Vol. 96, No. 2, pp.249-261.

Hopstaken, J.F., van der Linden, D., Bakker, A.B. and Kompier, M.A. (2015) 'The window of my eyes: task disengagement and mental fatigue covary with pupil dynamics', Biological Psychology, Vol. 110, No. 7, pp.100-106.

Hopstaken, J.F., van der Linden, D., Bakker, A.B., Kompier, M.A. and Leung, Y.K. (2016) 'Shifts in attention during mental fatigue: evidence from subjective, behavioral, physiological, and eye-tracking data', Journal of Experimental Psychology: Human Perception and Performance, Vol. 42, No. 6, pp.878-889.

Hulin, C.L. and Blood, M.R. (1968) 'Job enlargement, individual differences, and worker responses', Psychological Bulletin, Vol. 69, No. 1, p.41.

ISO 10075-1 (2019) Ergonomic Principles Related to Mental Workload - Part 1: General Issues and Concepts, Terms and Definitions, February [online] https://www.iso.org/obp/ui/\#iso:std:iso:10075:-1:ed-1:v1:en.

Johansson, G. (1989) 'Job demands and stress reactions in repetitive and uneventful monotony at work', International Journal of Health Services, Vol. 19, No. 2, pp.365-377.

Joyce, A. (2018) Boredom Numbs the Work World, March, The Washington Post [online] http://www.washingtonpost.com/wp-dyn/content/article/2005/08/09/AR2005080901395.html.

Knowles, D. and Tay, R. (2002) 'Driver inattention: more risky than the fatal four?', in Proceedings of the 2002 Road Safety Research, Policing and Education Conference, pp.87-91, Australasian College of Road Safety, Mawson, Australia.

Langheim, L., Matthews, G., Warm, J.S., Reinerman, L.E., Shaw, T.H., Finomore, V.S. and Guznov, S. (2007) 'The long pursuit: in search of predictors of individual differences in vigilance', in Thirteenth Meeting of the International Society or the Study of Individual Differences, Giessen, Germany.

Mael, F. and Jex, S. (2015) 'Workplace boredom: an integrative model of traditional and contemporary approaches', Group \& Organization Management, Vol. 40, No. 2, pp.131-159.

Manly, T., Robertson, I.H., Galloway, M. and Hawkins, K. (1999) 'The absent mind: further investigations of sustained attention to response', Neuropsychologia, Vol. 37, No. 6, pp.661-670.

Martin, M., Sadlo, G. and Stew, G. (2006) 'The phenomenon of boredom', Qualitative Research in Psychology, Vol. 3, No. 3, pp.193-211.

Martin, M., Sadlo, G. and Stew, G. (2012) 'Rethinking occupational deprivation and boredom', Journal of Occupational Science, Vol. 19, No. 1, pp.54-61.

McBride, S.A., Merullo, D.J., Johnson, R.F., Banderet, L.E. and Robinson, R.T. (2007) 'Performance during a 3-hour simulated sentry duty task under varied work rates and secondary task demands', Military Psychology, Vol. 19, No. 2, pp.103-117. 
Mehrabian, A. and Friedman, S.L. (1986) 'An analysis of fidgeting and associated individual differences', Journal of Personality, Vol. 54, No. 2, pp.406-429.

Mooneyham, B.W. and Schooler, J.W. (2013) 'The costs and benefits of mind-wandering: a review', Canadian Journal of Experimental Psychology/Revue Canadienne de Psychologie Expérimentale, Vol. 67, No. 1, p.11.

Morgan, K., Johnson, A.J. and Miles, C. (2014) 'Chewing gum moderates the vigilance decrement', British Journal of Psychology, Vol. 105, No. 2, pp.214-225.

O'Hanlon, J.F. (1981) 'Boredom: practical consequences and a theory', Acta Psychologica, Vol. 49, No. 1, pp.53-82.

Parasuraman, R. (1979) 'Memory load and event rate control sensitivity decrements in sustained attention', Science, Vol. 205, No. 4409, pp.924-927.

Pattyn, N., Neyt, X., Henderickx, D. and Soetens, E. (2008) 'Psychophysiological investigation of vigilance decrement: boredom or cognitive fatigue?', Physiology \& Behavior, Vol. 93, Nos. 1-2, pp.369-378.

Pekrun, R., Goetz, T., Daniels, L.M., Stupnisky, R.H. and Perry, R.P. (2010) 'Boredom in achievement settings: exploring control-value antecedents and performance outcomes of a neglected emotion', Journal of Educational Psychology, Vol. 102, No. 3, pp.531-549.

Perkins, R.E. and Hill, A.B. (1985) 'Cognitive and affective aspects of boredom', British Journal of Psychology, Vol. 76, No. 2, pp.221-234.

Proctor, R.W. and Van Zandt, T. (1994) Human Factors in Simple and Complex Systems, Allyn \& Bacon, Needham Heights, MA.

Provine, R.R. and Hamernik, H.B. (1986) 'Yawning: effects of stimulus interest', Bulletin of the Psychonomic Society, Vol. 24, No. 6, pp.437-438.

Putnam, S.P., Gartstein, M.A. and Rothbart, M.K. (2006) 'Measurement of fine-grained aspects of toddler temperament: the early childhood behavior questionnaire', Infant Behavior and Development, Vol. 29, No. 3, pp.386-401.

Ribot, T. (1890) The Psychology of Attention, Open Court Publishing Company, Chicago, IL.

Robertson, I.H., Manly, T., Andrade, J., Baddeley, B.T. and Yiend, J. (1997) 'Oops: performance correlates of everyday attentional failures in traumatic brain injured and normal subjects', Neuropsychologia, Vol. 35, No. 6, pp.747-758.

Rosenberg, M., Noonan, S., DeGutis, J. and Esterman, M. (2013) 'Sustaining visual attention in the face of distraction: a novel gradual-onset continuous performance task', Attention, Perception, \& Psychophysics, Vol. 75, No. 3, pp.426-439.

Satchell, P.M. (1993) Cockpit Monitoring and Alerting Systems, Ashgate, Brookfield, VT.

Scerbo, M.W. (1998) 'What's so boring about vigilance?', in Hoffman, R.R., Sherrick, M.F. and Warm, J.S. (Eds.): Viewing Psychology as a Whole: The Integrative Science of William N. Dember, pp.145-166, American Psychological Association, Washington, DC.

Scerbo, M.W., Greenwald, C.Q. and Sawin, D.A. (1992) 'Vigilance: it's boring, it's difficult and I can't do anything about it', Proceedings of the Human Factors Society 36th Annual Meeting, Vol. 36, pp.1508-1512.

Schaufeli, W.B. and Salanova, M. (2014) 'Burnout, boredom and engagement at the workplace', in Peeters, M.C.W., de Jonge, J. and Taris, T.W. (Eds.): People at Work: An Introduction to Contemporary Work Psychology, pp.293-320, Wiley, Hoboken.

Schooler, J.W. (2002) 'Re-representing consciousness: dissociations between experience and meta-consciousness', Trends in Cognitive Sciences, Vol. 6, No. 8, pp.339-344.

Seli, P., Carriere, J.S., Thomson, D.R., Cheyne, J.A., Martens, K.A.E. and Smilek, D. (2014) 'Restless mind, restless body', Journal of Experimental Psychology: Learning, Memory, and Cognition, Vol. 40, No. 3, p.660.

Seli, P., Risko, E.F., Smilek, D. and Schacter, D.L. (2016) 'Mind-wandering with and without intention', Trends in Cognitive Sciences, Vol. 20, No. 8, pp.605-617.

Smith, R.P. (1981) 'Boredom: a review', Human Factors, Vol. 23, No. 3, pp.329-340. 
Schneider, S.M. (2012) The Science of Consequences: How They Affect Genes, Change The Brain, and Impact Our World, Prometheus Books, New York.

Sokal, R.R. and Rohlf, F.J. (1995) Biometry: The Principles and Practice of Statistics in Biological Research, 3rd ed., W.H. Freeman, New York, New York, USA.

Stearman, E.J. and Durso, F.T. (2016) 'Vigilance in a dynamic environment', Journal of Experimental Psychology Applied, Vol. 22, No. 1, pp.107-123.

Thompson, W.T., Lopez, N., Hickey, P., DaLuz, C., Caldwell, J.L. and Tvaryanas, A.P. (2006) Effects of Shift Work and Sustained Operations: Operator Performance in Remotely Piloted Aircraft (OP-REPAIR), No. HSW-PE-BR-TR-2006-0001, Human Systems Wing (311th) Brooks AFB TX.

Tiwari, T., Singh, A.L. and Singh, I.L. (2009) 'Task demand and workload: effects on vigilance performance and stress', Journal of the Indian Academy of Applied Psychology, Vol. 35, No. 2, pp.265-275.

van Hooff, M.L. and van Hooft, E.A. (2014) 'Boredom at work: Proximal and distal consequences of affective work - related boredom', Journal of Occupational Health Psychology, Vol. 19, No. 3, pp.348-359.

van Tilburg, W.A. and Igou, E.R. (2012) 'On boredom: lack of challenge and meaning as distinct boredom experiences', Motivation and Emotion, Vol. 36, No. 2, pp.181-194.

Woods, D.W. and Miltenberger, R.G. (1996) 'Are persons with nervous habits nervous? A preliminary examination of habit function in a nonreferred population', Journal of Applied Behavior Analysis, Vol. 29, No. 2, pp.259-261.

Zuckerman, M., Kolin, E.A., Price, L. and Zoob, I. (1964) 'Development of a sensation-seeking scale', Journal of Consulting Psychology, Vol. 28, No. 6, pp.477-482. 